\title{
Research in Clinical Laboratory Science: Professionals' Educational Preparation
}

\section{REBECCA LAUDICINA, JOANN FENN, VICKIE FREEMAN, CAROL MCCOY, MARY ANN MCLANE, LILLIAN MUNDT, JOAN POLANCIC, TIM RANDOLPH, KRISTY SHANAHAN}

\section{LEARNING OBJECIVES}

1. Identify CLS practitioners' sources of knowledge of research principles and hands-on research training.

2. List activities that CLS practitioners believe would help improve their research skills.

3. Describe research components of CLS educational programs.

4. Characterize activities included in CLS undergraduate and master's student research projects.

5. List perceived barriers to research participation by undergraduates and master's students in CLS educational programs.

OBJECTIVE: To describe the educational preparation of CLS professionals for conducting research.

DESIGN: A link to 3-part online survey was sent by electronic mail to 7,572 members of the American Society for Clinical Laboratory Science and 500 program directors

SETTING: email message, on-line survey

PARTICIPANTS: all ASCLS members and all directors of accredited clinical laboratory educational programs

MAIN OUTCOME MEASURES: Quantitative and qualitative measures of professionals' educational preparation for conducting research and descriptions of program curricula in research.

RESULTS: 556 of 7572 (7.3\%) persons completed the survey. Twenty-two percent of CLS undergraduate educational programs offer a separate research course in the curriculum, and $37 \%$ require completion of a research project. Barriers to participation in research by undergraduates include time limitations within the curriculum, insufficient faculty time, and lack of funds, space, and equipment. Increased emphasis on developing research skills is found in educational programs at the master's degree level.

CONCLUSIONS: The formal educational background of many CLS professionals may leave them unprepared or underprepared for conducting research. Although there was broad representation among participants across educational levels, employment settings, and job positions, the number of survey respondents was limited. Possible directions for future research include conducting this survey using members of additional professional organizations.

ABBREVIATIONS: CLS = clinical laboratory science; ASCLS = American Society for Clinical Laboratory Science; NAACLS = National Accrediting Agency for Clinical Laboratory Science

INDEX TERMS: research activity, education

Clin Lab Sci 2011;24(4):243

JoAnn P. Fenn, M.S., MT(ASCP), Department of Pathology, University of Utah School of Medicine, Salt Lake City, UT

Vickie Freeman, Ph.D., MLS(ASCP $)^{C M} S C, F A C B$, University of Texas Medical Branch, Galveston, TX

Carol McCoy, Ph.D., MLS(ASCP) ${ }^{C M}$, Fairview Health Services. Minneapolis, $M N$ 


\section{FOCUS: BUILDING RESEARCH THROUGH MLS CURRICULA}

Mary Ann McLane, Ph.D., MLS(ASCP $)^{C M}$, University of Delaware, Newark, DE

Lillian A. Mundt, Ed.D., MLS(ASCP)SH, Adventists Health System Midwest, Hinsdale, IL

Joan Polancic, M.S.Ed., MLS, American Society for Clinical Laboratory Science, Washington, DC

Tim Randolph, Ph.D., MLS(ASCP), Saint Louis University, Saint Louis, MO

Kristy Shanahan, M.S., MLS(ASCP $)^{C M}$, Rosalind Franklin University of Medicine and Science, North Chigaco, IL

Address for Correspondence: Rebecca Laudicina, Ph.D., MLS(ASCP) ${ }^{C M}$, The University of North Carolina at Chapel Hill, 4110 Bondurant Hall, CB\# 7145, Chapel Hill, NC 27599-7145, (919) 8434350,rebecca_laudicina@med.unc.edu

\section{INTRODUCTION}

A task force consisting of nine members of the American Society for Clinical Laboratory Science (ASCLS) was created in October 2008 by the ASCLS leadership, including ASCLS president-elect Mary Ann McLane. The task force was charged with studying the state of research in the clinical laboratory science profession. At that time there was a perceived need for increased attention focused on research related to the practice of clinical laboratory science, especially by members of the profession. The ASCLS Research Task Force, consisting of members from various institutions, met for several months through conference telephone calls from 2008 to 2009. In addition to studying research activities, the Research Task Force chose to describe CLS professionals' educational preparation for conducting research.

The Research Task Force developed a three part survey consisting of 42 items. The first section was to be completed by all participants and assessed demographic characteristics of participants, opinions about research, involvement in research, and barriers to conducting research. Section 2 was to be completed only by CLS professionals who were currently doing research or had done research in the past. Results obtained from survey section 1 and 2 are described in a second article which accompanies this one. Survey section 3 was targeted to program directors of CLS undergraduate and graduate programs. A 3-part online survey using the SurveyMonkey $^{\mathrm{TM}}$ platform was developed. Survey distribution and results analysis were sponsored by ASCLS.

The focus of this part of the project was to determine CLS professionals' educational preparation for conducting research. Not surprisingly, clinical laboratory science curricular requirements for content related to research vary by program educational level. The National Accrediting Agency for Clinical Laboratory Science (NAACLS) accreditation guide states under a description of career entry that, "The Clinical Laboratory Scientist/Medical Technologist will also possess basic knowledge, skills, and relevant experience in research design/practice sufficient to evaluate published studies as an informed consumer." For doctoral programs in clinical laboratory science (DCLS), curricular requirements include, "Capstone experience, applied research, or translational research as required by the degree. Integral components will include research design, statistics, grant writing, protection of human subjects, and research ethics". ${ }^{2}$ Because NAACLS has no published standards specific to the curriculum in master's degree level clinical laboratory science programs, there are no curricular guidelines for programs at this level. Research is not included in the curricular requirement in the NAACLS document for Clinical/Medical Laboratory Technicians (CLT/MLT). ${ }^{3}$ Because educational programs in clinical laboratory science do not necessarily include research in the curriculum, survey items for this project addressed alternative means of acquiring research skills.

\section{MATERIALS AND METHODS}

Instructions and a link to an online 42 item survey developed by the ASCLS Research Task Force were emailed in May 2009 to 7,572 individuals who were either members of the American Society for Clinical Laboratory Science or program directors of NAACLS accredited two-year, four-year, and graduate educational programs. A second email message was sent to the mailing list as a reminder prior to the survey closing. Data from the survey results was collected following closing of survey availability one month later. There was no attempt to collect or retain participant identifiers in 


\section{FOCUS: BUILDING RESEARCH THROUGH MLS CURRICULA}

this study. The study was approved by the University of Utah Institutional Review Board.

\section{RESULTS}

Demographics

Completion of the 19 items in this section was requested of all survey participants. Responses to the online survey were received from 556 persons, or $7 \%$ of those surveyed. Females comprised $83 \%$ of the sample. Eighty two percent of respondents were working fulltime, $10 \%$ were working part-time, and $7 \%$ were not currently working. Participants' employment setting included: community hospital $24 \%$ of respondents, urban hospital 21\%, 4-year college/university $16 \%$, academic medical center 11\%, 2-year college $8 \%$, reference laboratory $6 \%$, physicians' office laboratory $4 \%$, industry 4\%, and "other" 6\%. Participants' job position/title included: technical staff $32 \%$ of respondents, educator $32 \%$, supervisor/manager $26 \%$, student 3\%, researcher 2\%, and "other" $6.0 \%$. Respondents' highest education levels included: associate's degree $6 \%$, bachelor of science (B.S.) 46\%, master of science (M.S.) 33\%, doctor of philosophy (Ph.D.) 10\%, associate's degree 6\%, doctor of education (Ed.D) 1\%, and "other" 4\%.

Participants were asked to identify the sources of their knowledge of research principles and sources of handson training experiences, and those results are listed in Table 1. Formal education, including undergraduate and graduate, were most frequently identified as the source of knowledge of research principles and handson experience. Almost one-fourth of respondents indicated that they had not learned how to conduct research, and over one-fourth had no hands-on research training.

Participants also identified activities that they perceived would help them improve their research skills. Mentoring by colleagues who are conducting research was listed by $50.9 \%$ of respondents, and attending presentations or workshops at professional meetings was cited by $45.7 \%$ of respondents. Other activities included reading articles in professional journals $(31.3 \%)$, taking online credit courses or degree programs $(30.2 \%)$, enrolling in traditional courses or degree programs (19.4\%), and "other" 6.5\%. Almost $30 \%$ of 464 survey participants indicated they are not interested in conducting research.
Table 1. Sources of knowledge of research principles/fundamentals and hands on research training experiences. $(\mathrm{N}=497)$

\begin{tabular}{lcc}
\hline Source & $\begin{array}{c}\text { Response } \\
\%\end{array}$ & $\begin{array}{c}\text { Response } \\
\%\end{array}$ \\
& $\begin{array}{c}\text { Knowledge of } \\
\text { research } \\
\text { principles/ } \\
\text { fundamentals* }\end{array}$ & $\begin{array}{c}\text { Hands-on } \\
\text { research } \\
\text { training* }\end{array}$ \\
& & \\
& 39.4 & 32.9 \\
& 36.6 & 29.8 \\
Undergraduate education & 26.8 & 31.6 \\
Graduate school & NA \\
Boss/mentor/colleagues on the job & NA & 28.9 \\
Have NOT learned how to conduct research & NA \\
Never had hands-on research training & 20.1 & 18.2 \\
Professional development opportunities & 16.1 & 3.6 \\
On my own due to trial and error & 3.4 & \\
Other & &
\end{tabular}

* Respondents could check all that apply.

$\mathrm{NA}=$ not applicable

\section{Data from Educational Programs}

Respondents to items in this section consisted of directors of baccalaureate level programs (57\%), associate degree programs (35\%), master's degree programs $(12 \%)$, and doctoral degree programs $(1 \%)$ (Some respondents directed more than one program level.) A total of $18 \%$ of program directors indicated that there was a separate research course in their undergraduate curriculum ranging from 1 to more than 4 credits. Twenty-eight percent of program directors indicated that a hands-on research project is required of their undergraduate students, $9 \%$ indicated that a research project is optional, and $63 \%$ indicated that research is not required.

Among undergraduate programs in which a research project is included, $36 \%$ of programs have 1 to 5 students engaged in research at any given time, $31 \%$ have 6 to 10 students, $15 \%$ have 11 to 15 students, and $18 \%$ have 16 or more students conducting research. The amount of time allowed for undergraduate project completion ranges from 1 to $>6$ months. Requirements, other curricular aspects, and collaborators for student research projects are contained in Tables 2 and 3, respectively. Perceived barriers to conducting student research are cited in Table 4.

Eight of twelve survey respondents (67\%) indicated that a hands-on research project is required of master's level 
Table 2. Aspects of students' research projects.

\begin{tabular}{|c|c|c|c|c|}
\hline Activity* & Frequency & $\%$ & Frequency & $\%$ \\
\hline & $\begin{array}{l}\text { Under } \\
\text { graduate } \\
\text { students } \\
\mathrm{N}=43\end{array}$ & $\begin{array}{l}\text { Under } \\
\text { graduate } \\
\text { students }\end{array}$ & $\begin{array}{c}\text { Master's } \\
\text { students } \\
\mathrm{N}=13\end{array}$ & $\begin{array}{l}\text { Master's } \\
\text { students }\end{array}$ \\
\hline Written paper required & 33 & 76.7 & 12 & 92.3 \\
\hline Oral presentation required & 30 & 69.8 & 10 & 76.9 \\
\hline Poster required & 18 & 41.9 & 1 & 7.7 \\
\hline Paper submission for publication encouraged & 17 & 39.5 & 10 & 76.9 \\
\hline Students work independently with mentor & 17 & 39.5 & 10 & 76.9 \\
\hline All typical aspects completed by student (proposal, budget, results, etc.) & 12 & 27.9 & 6 & 46.2 \\
\hline Students assist in an existing research study & 11 & 25.6 & 4 & 30.8 \\
\hline Paper submission for publication required & NA & NA & 2 & 15.4 \\
\hline Other & 2 & 4.6 & - & - \\
\hline
\end{tabular}

${ }^{*}$ Respondents could check all that apply.

$\mathrm{NA}=$ not applicable

students in clinical laboratory science. Four (33\%) indicated that a research project was not required. Project length varied, ranging from 2 to 4 months (31\% respondents), 6 to 9 months (15\% respondents), and more than 9 months (54\% respondents). Requirements, other curricular aspects, and collaborators for students' master's level research projects are listed in Tables 2 and 3 , respectively. Barriers to master's level students participating in research projects are cited in Table 4. Insufficient responses were received from doctoral programs to report findings.

Table 3. Student research project collaborators.

\begin{tabular}{lcccc}
\hline Collaborators & $\begin{array}{c}\text { Frequency } \\
\text { Undergraduate graduate } \\
\text { N = 41 }\end{array}$ & $\begin{array}{c}\text { \% Under- } \\
\text { Faster's } \\
\text { N = 12 }\end{array}$ & $\begin{array}{c}\% \\
\text { Master's }\end{array}$ \\
\hline $\begin{array}{l}\text { Instructors or staff } \\
\text { at clinical affiliates }\end{array}$ & 25 & 61.0 & 7 & 58.3 \\
$\begin{array}{l}\text { CLS faculty only } \\
\text { Any faculty at }\end{array}$ & 19 & 46.3 & 9 & 75.0 \\
the institution & 19 & 46.3 & 10 & 83.3 \\
$\begin{array}{l}\text { Fellow students, } \\
\text { in groups }\end{array}$ & 14 & 34.1 & 2 & 16.7 \\
$\begin{array}{l}\text { No collaborators, } \\
\text { work done independently }\end{array}$ & 1 & 2.4 & 1 & 8.3 \\
\hline
\end{tabular}

*Respondents could check all that apply
Table 4. Barriers to research participation for students. $(\mathrm{N}=91)$

\begin{tabular}{lcccc}
\hline Collaborators & $\begin{array}{c}\text { Frequency } \\
\text { Undergraduate } \\
\text { N = 91 }\end{array}$ & $\begin{array}{c}\text { \% Under } \\
\text { graduate }\end{array}$ & $\begin{array}{c}\text { Frequency } \\
\text { Master's } \\
\mathrm{N}=12\end{array}$ & $\begin{array}{c}\% \\
\text { Master's }\end{array}$ \\
\hline $\begin{array}{l}\text { Time limitations } \\
\text { in curriculum }\end{array}$ & 81 & 89.0 & 10 & 71.4 \\
$\begin{array}{l}\text { Insufficient faculty time } \\
\text { to oversee research projects }\end{array}$ & 54 & 59.3 & 7 & 50.0 \\
$\begin{array}{l}\text { Lack of funds } \\
\text { Lack of supplies, }\end{array}$ & 49 & 53.8 & 10 & 71.4 \\
Equipment & 41 & 45.1 & 5 & 35.7 \\
$\begin{array}{l}\text { Lack of space } \\
\text { Insufficient faculty expertise }\end{array}$ & 26 & 28.6 & 5 & 35.7 \\
to oversee research projects & & 30.8 & 4 & 28.6 \\
Other & 8 & 8.8 & 1 & 7.7 \\
\hline
\end{tabular}

*Respondents could check all that apply.

\section{DISCUSSION}

There are several measures from the survey that suggest that we prepare only a portion of undergraduate students with the skills needed for conducting research. Over three-quarters of undergraduate programs do not include a separate research course in the curriculum, and $63 \%$ do not require participation in a research project. Of all survey respondents, $23 \%$ stated that they had not learned how to conduct research, and other respondents indicated that their knowledge of research 


\section{FOCUS: BUILDING RESEARCH THROUGH MLS CURRICULA}

principles came from graduate education, on the job mentoring, or professional development. Undergraduate education was cited by only $39 \%$ of respondents as a source of knowledge of research fundamentals and by only $33 \%$ of respondents as a source of hands-on research training. The most frequently cited barrier to research participation in undergraduate programs was time limitations imposed by the curriculum. Current NAACLS standards for the Clinical Laboratory Scientist/Medical Technologist limit knowledge of research to that sufficient to "evaluate published studies as an informed consumer" and do not require the ability to conduct research. ${ }^{1}$ If as a profession we believe that the ability to conduct research is important for baccalaureate-level practice, then program curricular standards will require adjustment.

Preparation for research involvement is greater in M.S. programs than in undergraduate programs. Two-thirds of programs responding require a hands-on research project, almost double the research involvement in undergraduate programs. It is noteworthy that not all master's degree programs participating in this study require students to conduct research. Time limitations within the curriculum and lack of funds were identified most frequently as barriers to graduate student research participation. Insufficient faculty time to oversee master's degree student projects was cited by $50 \%$ of respondents as an additional barrier.

Karni et al evaluated data regarding graduate degree programs in clinical laboratory science and concluded that both the number of advanced degree programs and the number of graduates are small and had decreased between 1990 and 2007. The 2007 Directory of Graduate Programs for Clinical Laboratory Practitioners listed 28 master's level programs and only 5 doctoral programs (Ph.D., Ed.D., or Doctor of Clinical Laboratory Science) in the U.S.A. ${ }^{4}$ Because relatively small numbers of clinical laboratory professionals are being educated at the graduate level, one way to increase research participation is to enhance the research skills expected of baccalaureate level students. Whether or not this is feasible or desirable is worthy of debate.

If the clinical laboratory science profession believes it is desirable to increase research involvement of baccalaureate level professionals, it appears that curricular standards may need to be revised. Programs may choose to add research courses and competencies, including hands-on projects. Articles by Rohde et al and Saleh and Hamed in a recent supplement of Clinical Laboratory Science present curricular models for preparing students to be both analytical consumers and producers of research in the profession. ${ }^{5,6}$

The authors recognize the limitations of this study. First, a 7\% response rate may appear insignificant and may provide a narrow perspective. Although there was broad representation among survey participants across educational levels, employment settings, and job positions, the number of survey respondents was limited. It is also noteworthy that data analysis described in this paper is at the descriptive level, with no t-tests or ANOVAs performed. Advanced statistical analysis could possibly reveal additional information.

Only ASCLS members and program directors were surveyed for this study. To gain a more complete assessment of research activity among clinical laboratory professionals, the survey could be sent to members of additional organizations, including the American Society for Microbiology, American Association for Clinical Chemistry, American Society for Clinical Pathology, and others. This would target clinical laboratory professionals who are not members of ASCLS but are members of other professional societies and who may engage in research and scholarly activities.

Because less than one-fourth of CLS undergraduate educational programs offer a separate research course in the curriculum and only about one-third require completion of a research project, the formal educational background of many CLS professionals may leave them inadequately prepared for conducting research. Barriers to participation in research identified by this study will require consideration by educators interested in adding research competencies to program curricula. Another approach to facilitating increased research involvement may lie in increasing the number of clinical laboratory professionals educated at the graduate level.

\section{REFERENCES}

1. NAACLS Guide to Accreditation: Section III for CLS/MT. Unique Standards and Documentation Required for Accredited CLS/MT programs. Rosemont IL. Section 22. Curricular Requirements. Accessed at http://www.naacls.org/ docs/Section3_CLS-MT.pdf on 2/17/11 
2. NAACLS Guide to Accreditation for Doctorate Programs in Clinical Laboratory Science. Rosemont IL;NAACLS Accessed at http://www.naacls.org/docs/guide_dcls.pdf on 2/17/11.

3. NAACLS guide to Accreditation: Section III for Accredited CLT/MLT Programs. Rosemont IL Unique Standards and Documentation Required for Accredited CLT/MLT programs. Section 22. Curricular Requirements. Accessed at http:// www.naacls.org/docs/Section3_CLS-MT.pdf on 2/17/11
4. Karni K, Polancic J, Fenn J, Spannaus-Martin DJ. Graduate education in clinical laboratory science. Is the glass half full or half empty? Clin Lab Sci 2010;23:166-74.

5. Rohde RE, Falleur DM, Redwine GD, Patterson TL. Growing our own: Teaching and doing research in CLS. Clin Lab Sci 2010;23 Suppl:3-11-8.

6. Saleh SM, Hamed KM. Preparing CLS professionals to be consumers and producers of research. Clin Lab Sci 2010;23 Suppl:3-19-23.

Member Renewal
Thank You!
ASCLS wants to THANK YOU for
renewing your membership for the 2011-
12 year!
ASCLS is offering 6 online quizzes at
no charge to help with your CE needs
For details* about the offer and
order form, go to www.ascls.org/
?Edu_MTY
We know you have choices as to
which organization you belong and we
are thrilled you chose ASCLS!
* For PF1,PF2 \& FYP members who
renewed by $9 / 30 / 11$
*Must complete quizzes by $7 / 31 / 12$

